\title{
RHEOLOGICAL PROPERTIES OF BITUMENS FROM THE PERSPECTIVE THEIR CHEMICAL COMPOSITION
}

\author{
Eva REMIŠOVÁ ${ }^{1, *}$, Gang LIU², Jozef KOMAČKA ${ }^{1}$, Shaopeng $\mathrm{WU}^{2}$, Yue XIAO², \\ Michal HOLÝ 1 \\ ${ }^{1}$ Department of Highway Engineering, Faculty of Civil Engineering, University of Žilina, Univerzitná \\ 8215/1, 01026 Žilina, Slovakia. \\ ${ }^{2}$ Wuhan University of Technology, Luoshi Road 122, Wuhan City, Hubei Province, China. \\ corresponding author: eva.remisova@fstav.uniza.sk.
}

\section{Abstract}

The quality of bituminous binders is commonly evaluated by the empirical tests. The functional approach to the evaluation of bitumen properties is a trend that has been applied in the last years. The dynamic shear rheometer (DSR) test has been widely used to determine the shear complex modulus of bitumen in the wide range of frequencies and temperatures. A lot of research works were focused on the effect of the chemical compounds of bitumen on the values of the shear complex modulus. The missing information related to the effect of the compound of bitumen on the elastic and plastic part of the shear complex modulus was input for the presented investigation. The significant effect on the elastic part of the complex modulus was determined only at the high temperatures $\left(60\right.$ and $\left.80{ }^{\circ} \mathrm{C}\right)$. The aromatics, resins and asphaltenes were identified as the influencing compounds. The important effect was also noted for the resins at the temperatures of 5 and $15{ }^{\circ} \mathrm{C}$. It was also concluded that the effect of the saturates on the elastic part of the shear complex modulus is marginal. The effect of the aromatics and asphaltenes on the plastic part of the shear complex modulus was identified only at the temperature of $80{ }^{\circ} \mathrm{C}$. The effect of these two compounds at other temperatures seems to be unimportant. The significant effect of the resins was stated for the temperatures of $15{ }^{\circ} \mathrm{C}$ and $5{ }^{\circ} \mathrm{C}$. Their effect at other temperatures can be supposed as marginal. The negligible effect of the saturates on the plastic part of the shear complex modulus was deducted.

The regression analysis of the chemical composition of the bitumen and the parts of the shear complex modulus at the temperature of $80{ }^{\circ} \mathrm{C}$ proved that the frequency of the DSR test can be a factor affecting the level of the relationship between the group composition of the bitumen and its rheological properties.
\end{abstract}

\section{Keywords:}

Bitumen; Penetration; Softening point; Modulus;

Frequency.

\section{Introduction}

Asphalt is one of the basic building materials that are mainly used in road construction. With the development of the use of bituminous binders in road construction, there is also the development of new test methods describing the properties of bitumen as accurately as possible. The behaviour of bituminous binders at high temperatures with a risk of permanent deformation is one of the most important. Furthermore, the determination of the resistance to low temperatures is used to assess the risk of a pavement failure by frost cracks. Also, the fatigue properties of the material must not be forgotten, or the resistance to loss of cohesion should be characterized.

The quality of bituminous binders is commonly evaluated by the empirical tests based on obtaining one values for specific boundary conditions. The consistencies for the mean operating temperatures (the penetration test) and for elevated operating temperatures (the softening point test) 
are assessed. However, these properties are not related to an asphalt composition and to the stresses corresponding to the load in a real pavement. The increase in the requirements for the properties of asphalt mixtures has caused, new ways and approaches to be sought to better describe the properties of the bituminous binders. The functional approach to the evaluation of bitumen properties is a trend that has been applied in last years.

In the case of functional characteristics, the behaviour of bitumen is determined as a result of repeated load, or the various forms of intervals (temperature, frequency, stress, strain) in which the bitumen is exposed. The dynamic shear rheometer (DSR) test has been widely used to determine the rheological properties of bitumen in the wide range of frequencies and temperatures that occur in the asphalt layers of a pavement. The relationship between the empirical tests and the rheological properties of bituminous binders, determined in the dynamic shear rheometer, has been the subject of research in several works (e.g. [1-5]).

However, the chemical perspective describes bitumen as a composite material that can easily be separated into two major fractions by the solvent extraction with n-heptane: (a) the insoluble fraction of asphaltenes, and (b) the soluble fraction, the maltenes - [6]. The soluble fraction can be split into three phases by column chromatography: saturates, aromatics (also apolar aromatics), and resins (also polar aromatics) - [7-8]. Different concentrations of asphaltenes in the bitumen have a significant influence on the rheological bitumen properties. Increasing the content of asphaltenes results in increasing hardness and viscosity [9] and shows an influence of the sensitivity of ageing [10]. In an interdisciplinary study the impact of the maltenes phase and asphaltenes on the linear viscoelastic behaviour and the microstructure of bitumen were analysed by creep recovery testing in a DSR and by atomic force microscopy (AFM) in [11]. The investigation [12] was focused on the relation between the logarithm of the shear modulus $\log \left|G^{*}\right|$ (and the phase angle $\delta$ ) and the bitumen fractions at different temperatures. The results of the multiple linear regression analyses showed that the complex modulus of the bitumen is dependent on both the contents and the molecular weight of the several bitumen fractions. The similar investigations can be found in other research works that deal with the effect of the compound of bitumen on rheological properties ([13-14]).

The missing information in the literature is, what is the effect of the compound of bitumen on the viscous and plastic part of the shear complex modulus. Therefore, the research on this topic was realized using four bitumens.

\section{Experimental}

The research was performed on the samples of the bitumens that are commonly used for the production of asphalt mixtures. Their parameters and the applied tests are described below. The results of the tests are presented and discussed and the conclusions are made based on the findings.

\subsection{Materials}

The samples of the tested bitumens composed of two paving grade bitumens (PGB) and two polymer modified bitumens (PMB) that were modified by Styrene-Butadiene-Styrene (SBS). The overview is in Table 1.

Table 1: Tested PGB and PMB bitumens.

\begin{tabular}{|c|c|c|c|c|}
\hline & A4 & A11 & M2 & M11 \\
\hline Type & $50 / 70$ & $35 / 50$ & $45 / 80-75$ & $25 / 55-60$ \\
\hline Producer & Lotos & Orlen & OMV & Total \\
\hline
\end{tabular}

\subsection{Tests of the bitumens}

The standard penetration and softening point tests according to [15] and [16] were used to determine the basic parameters of the bitumens. The composition of the bitumens was investigated using the Saturate, Aromatic, Resin and Asphaltene (SARA) analysis and the elementary analysis (C, $\mathrm{H}, \mathrm{N}, \mathrm{S}$ content). The rheological properties of the bitumens were tested using the Dynamic Shear Rheometer test (DSR) according to [17].

The combination of the extraction of asphaltenes using $n$-heptane and the liquid chromatography was used for the (SARA) analysis. The method of burning the sample in the flow of oxygen was applied for determining the elementary composition, i.e., the determination of the content 
of $\mathrm{C}, \mathrm{N}, \mathrm{H}$, and $\mathrm{S}$. The gaseous combustion products $\left(\mathrm{N}_{2}, \mathrm{CO}_{2}, \mathrm{H}_{2} \mathrm{O}\right.$, and $\left.\mathrm{SO}_{2}\right)$ were purified, separated into the components and analysed on a TCD detector.

DSR tests were performed to analyse the rheological properties of the bitumens. The tests were performed according to EN 14770 with the controlled shear loading. The parameters of the test are given in Table 2. Before starting the DSR measurement, strain sweeps were performed to determine the linear viscoelastic region of the binder. The storage modulus, loss modulus, complex modulus and phase angle were determined using the recorded response of the sample to the load.

Table 2: Parameters of the DSR test.

\begin{tabular}{|c|c|c|c|}
\hline Diameter of the plate $[\mathrm{mm}]$ & Test temperature $\left[{ }^{\circ} \mathbf{C}\right]$ & Gap $[\mathrm{mm}]$ & Frequency $[\mathrm{Hz}]$ \\
\hline 5 & $25,30,40,50,60,80$ & 1 & $0.1 \sim 10$ \\
\hline 8 & $-5,5,15,25,30$ & 2 & $0.1 \sim 10$ \\
\hline
\end{tabular}

\subsection{Test results and discussion}

The results of the penetration and the softening point test proved the expected difference in these values (Table 3).

Based on current knowledge and the results of the standard tests, the difference in the composition of asphaltenes, maltenes, saturates and resins among the bitumens was expected. The SARA analysis proved that some differences exist (Fig. 1) but they are not very significant. An even smaller difference was observed for the elemental composition of the bitumen (Table 4). As for the bitumen A4, A11 and M2, it can be stated, that the elemental composition of these binders is almost identical. Some minor difference can be observed in the content of the elements in the case of the bitumen M11.

Table 3: Basic parameters of the tested bitumen.

\begin{tabular}{|c|c|c|c|c|}
\hline & A4 & A11 & M2 & M11 \\
\hline Penetration $\left[\mathrm{mm} \times 10^{-1}\right]$ & 61.0 & 40.8 & 54.6 & 37.6 \\
\hline Softening point $\left[{ }^{\circ} \mathrm{C}\right]$ & 48.0 & 53.5 & 80.8 & 62.0 \\
\hline
\end{tabular}

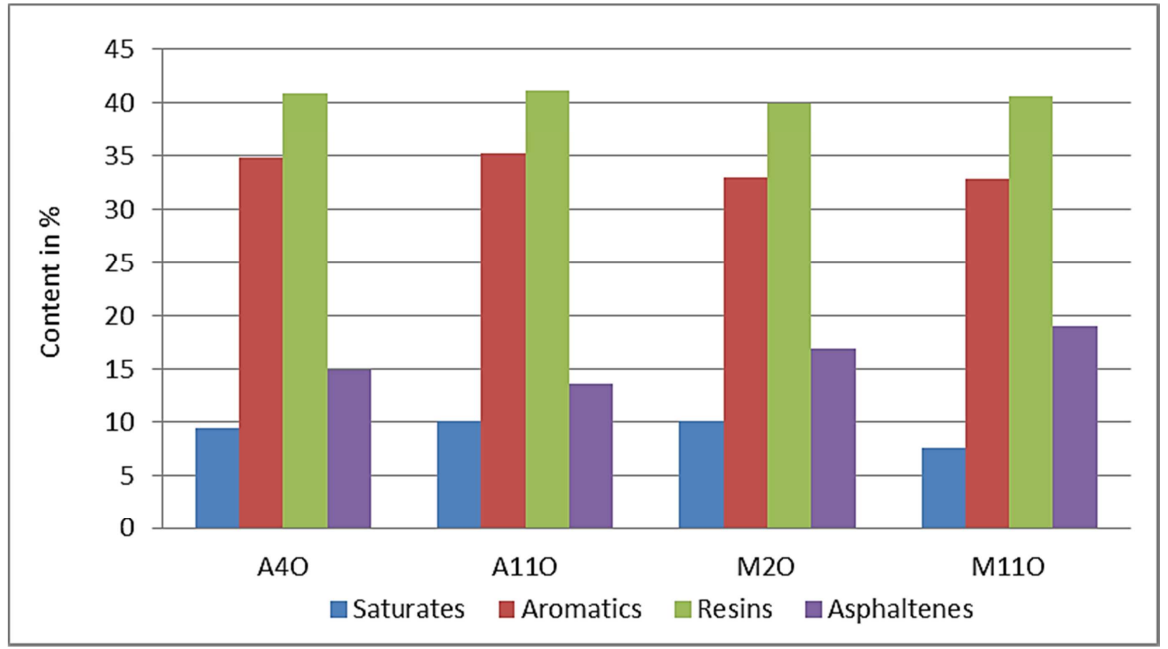

Fig. 1: SARA analysis results.

Table 4: Elementary analysis results.

\begin{tabular}{|c|c|c|c|c|}
\hline \multirow{2}{*}{ Element } & \multicolumn{4}{|c|}{ Content in \% } \\
\cline { 2 - 5 } & A4 & A11 & M2 & M11 \\
\hline Carbon & 84.46 & 84.17 & 84.31 & 85.05 \\
\hline Hydrogen & 10.15 & 10.30 & 10.24 & 10.15 \\
\hline Nitrogen & 0.586 & 0.450 & 0.476 & 0.750 \\
\hline Sulphur & 4.363 & 4.300 & 4.721 & 3.260 \\
\hline
\end{tabular}


Despite the small differences in the group and elementary composition, the DSR test showed the different rheological behaviour the tested bitumens. The master curves calculated for the temperature of $25^{\circ} \mathrm{C}$ proved the change of the complex modulus (Fig. 2) and the phase angle (Fig. 3) in the whole range of the load frequencies.

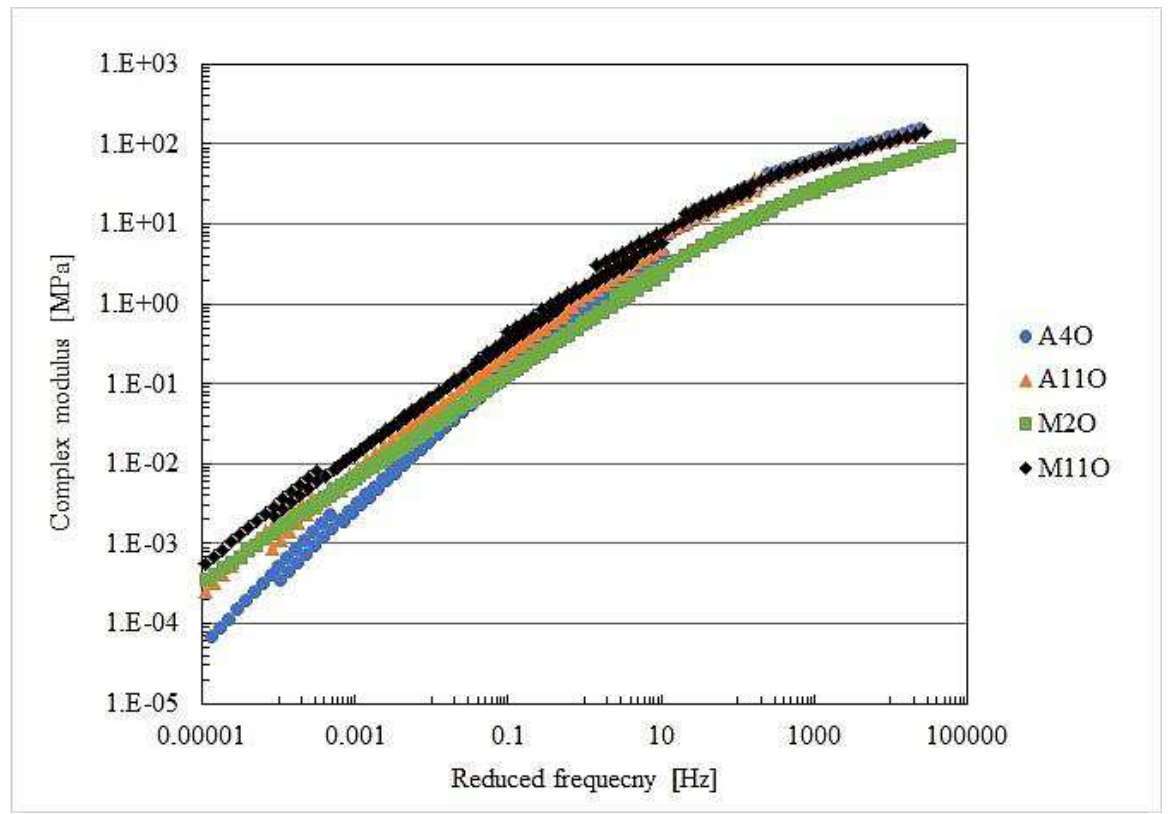

Fig. 2: Master curves of the complex modulus.

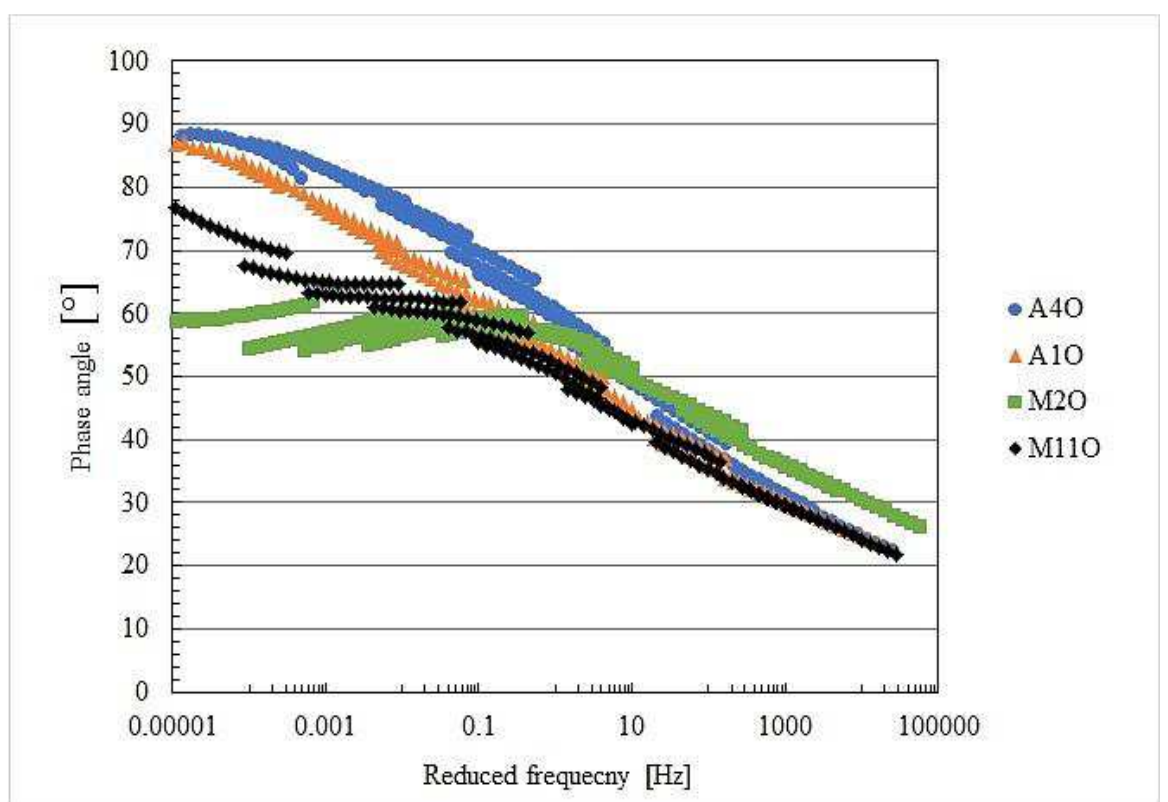

Fig. 3: Master curves of the phase angle.

It is evident from the figures above that the stiffness of the PMB is higher in the lower frequencies compared to the stiffness of PGB. However, the complex modulus of the PGB 35/50 (A11) is close to the values of the PMB. When the frequency increases, the change of the stiffness of the PGB is a little bit faster compared to the stiffness of the PMB and the difference in the complex modulus decreases. An interesting fact is, that the complex modulus of the PMB 45/80-75 (M2O) is the lowest at the frequencies above $10 \mathrm{~Hz}$. The master curves of the phase angle clearly demonstrate the difference between the PGB and PMB. The lower phase angle of the PMB (M2O and M11O) confirms more elastic behaviour of both PMB. However, only the PMB 45/80-75 (M2O) behaves as a polymer modified binder (the master curve of the phase angle declines as the frequency decreases lower than $10^{-2} \mathrm{~Hz}$ ). The PMB 25/55 - 60 (M110) is more close to the PGB binders. 
The effect of the chemical composition of the bitumen on its rheological properties was investigated only in relation to the components of the complex modulus, i.e. the real (elastic) and imaginary (plastic) part. The values determined at all test temperatures for the frequency of $1.29 \mathrm{~Hz}$ were used for the regression analysis with the individual compounds of the bitumen. The example is given in Fig. 4.

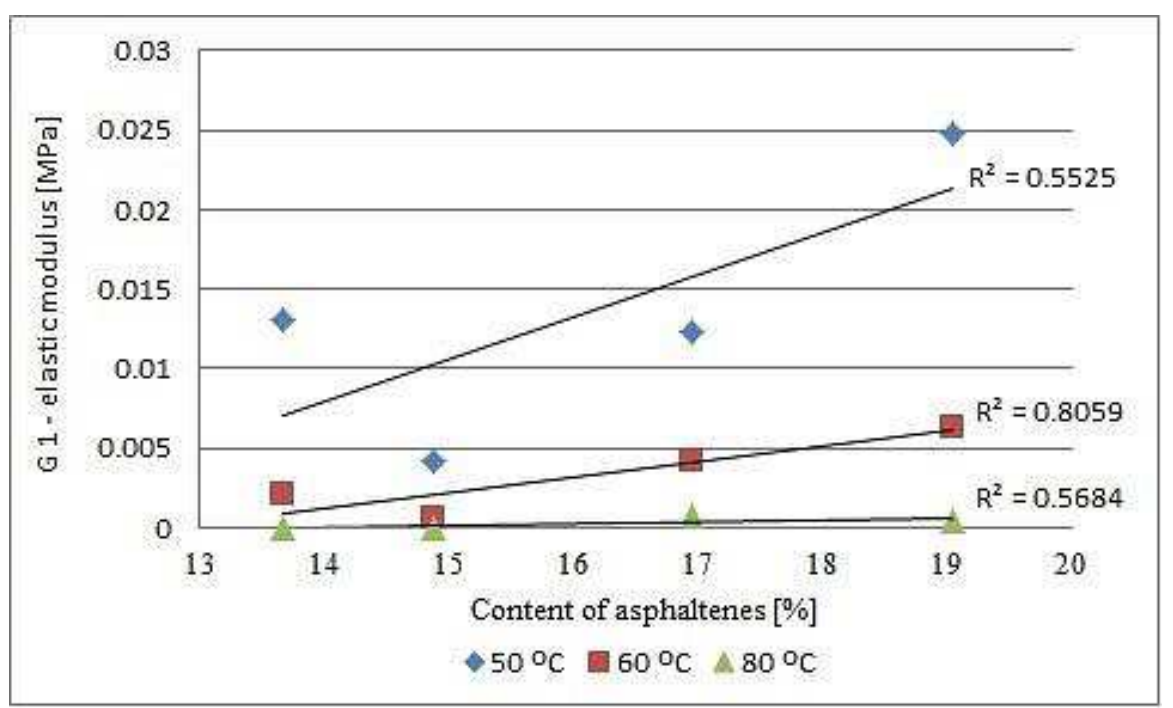

Fig. 4: Relationship between the content of the asphaltenes and the elastic part of the shear complex modulus at the frequency of $1.29 \mathrm{~Hz}$.

The relationship was assessed using linear regression. The effect of the differences in the content of a compound of bitumen on the variation in the values of the elastic (or plastic) modulus was expressed by the coefficient of determination $R^{2}$. The values varied in the wide range for both parts of the complex modulus (Fig. 5 and 6). Moreover, the $R^{2}$ values for one compound also varied in the range of the test temperatures.

The significant effect on the elastic part of the complex modulus at the high temperatures $(60$ and $80^{\circ} \mathrm{C}$ ) should have the aromatics, resins and asphaltenes. The $R^{2}$ values are higher than 0.8 that can be assessed as the strong effect these compounds at these temperatures. Based on the $R^{2}$ values, the important effect could also have the resins at the temperatures of 5 and $15{ }^{\circ} \mathrm{C}\left(R^{2}\right.$ above $0.7)$. At other temperatures, the $R^{2}$ values for the aromatics, resins and asphaltenes are relatively low and it is not a reason to suppose their effect on the elastic part of the shear complex modulus. The effect of saturates on the elastic part of the shear complex modulus can be assessed as marginal. The higher $R^{2}$ values are at about 0.5 (the temperatures between 25 and $60{ }^{\circ} \mathrm{C}$ ). The $R^{2}$ values at other temperatures are even much lower.

As for the effect of the compound on the plastic part of the shear complex modulus, only the aromatics and asphaltenes at the temperature of $80{ }^{\circ} \mathrm{C}$ could be significant. The effect of these two compounds at other temperatures seems to be unimportant because of the low coefficient of determination. The significant effect of the resins can be stated for the temperatures of $15^{\circ} \mathrm{C}$ and $5{ }^{\circ} \mathrm{C}$ ( $R^{2}$ above 0.8 and 0.7 respectively). The $R^{2}$ values at other temperatures are mostly below 0.5 . Therefore, the marginal effect of the resins can be supposed at these temperatures. The effect of saturates on the plastic part of the shear complex modulus is identical to their effect on the elastic part. Due to the $R^{2}$ values lower than 0.55 can be evaluated as negligible.

The previous $R^{2}$ values were determined only for the frequency of $1.29 \mathrm{~Hz}$. To verify the change of the coefficient of determination with frequency, the regression analysis was used to determine the $R^{2}$ values (Fig. 6). This procedure was executed for the temperature of $80^{\circ} \mathrm{C}$. The reason for this was that the highest $R^{2}$ values at the frequency of $1.29 \mathrm{~Hz}$ were observed at this temperature. 


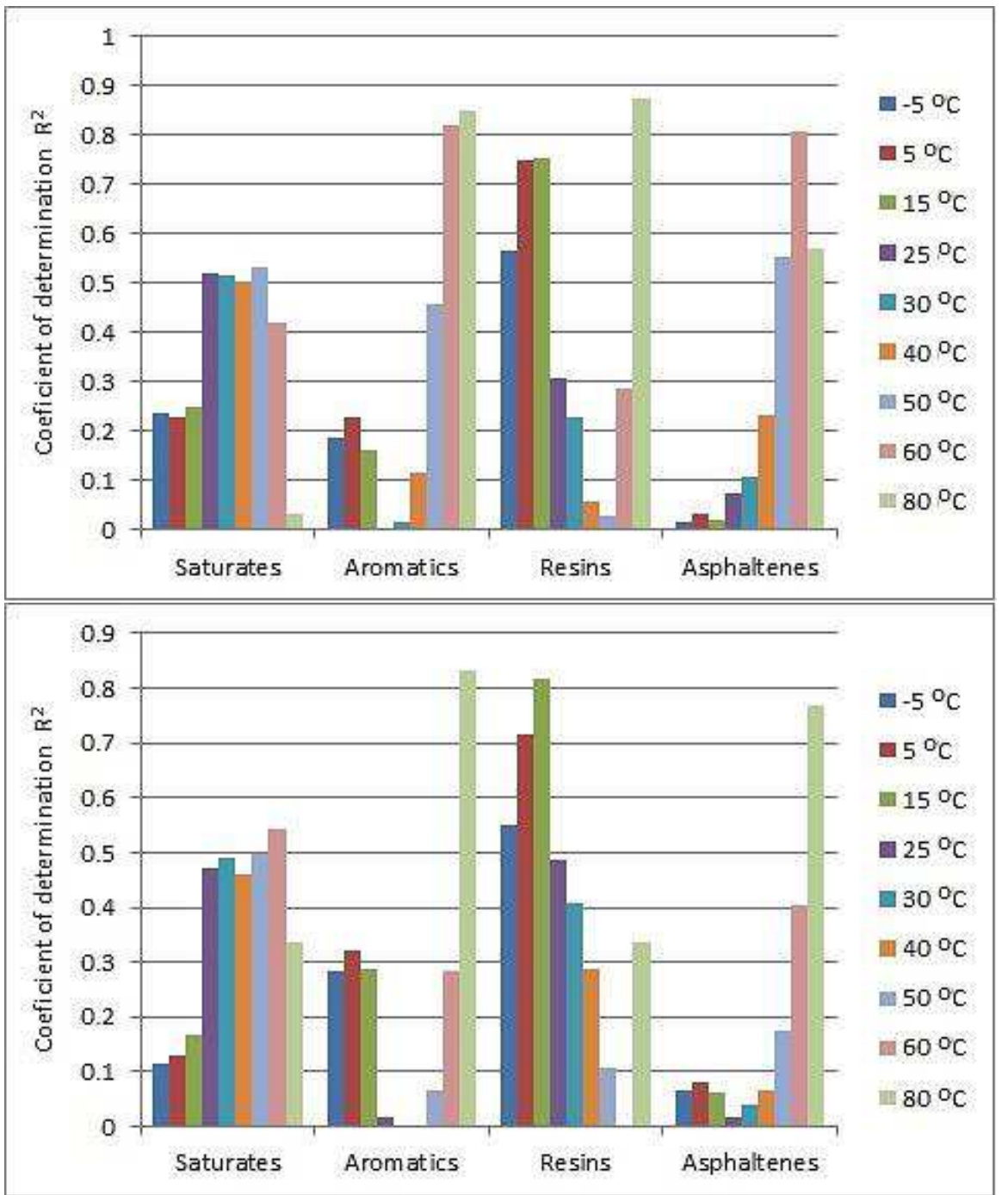

Fig. 5: Coefficient of determination for the elastic (left) and plastic (right) part of the shear complex modulus (frequency $1.29 \mathrm{~Hz}$ ).

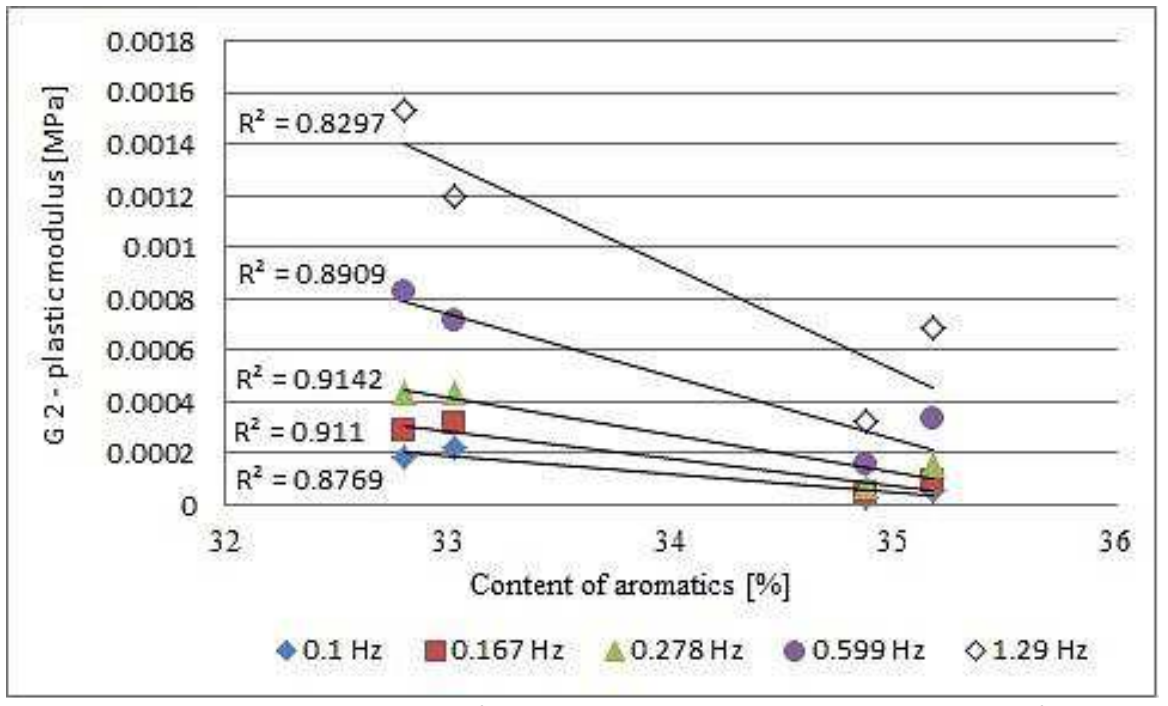

Fig. 6: Relationship between the content of the aromatics and the plastic part of the shear complex modulus (temperature $80^{\circ} \mathrm{C}$ ). 
The course of the $R^{2}$ values (Fig. 7) confirms that the frequency of the DSR test can be a factor affecting the level of the relationship between the group composition of the bitumen and its rheological properties (elastic and plastic part of the shear complex modulus).

The highest $R^{2}$ values determined for the aromatics and resins at the frequency of $1.29 \mathrm{~Hz}$, in the case of the elastic part of the complex modulus, have a different course at other frequencies. The $R^{2}$ values for the resins increase for the lower frequencies and decrease for the frequencies higher than $1.29 \mathrm{~Hz}$. However, the change of the $R^{2}$ values for the aromatics is opposite (the lower values for the lower frequencies and vice versa). The significant effect of the frequency was observed in the case of the asphaltenes. The $R^{2}$ value importantly increases at the frequencies above $1.29 \mathrm{~Hz}$ and reaches the values up to 0.8 .

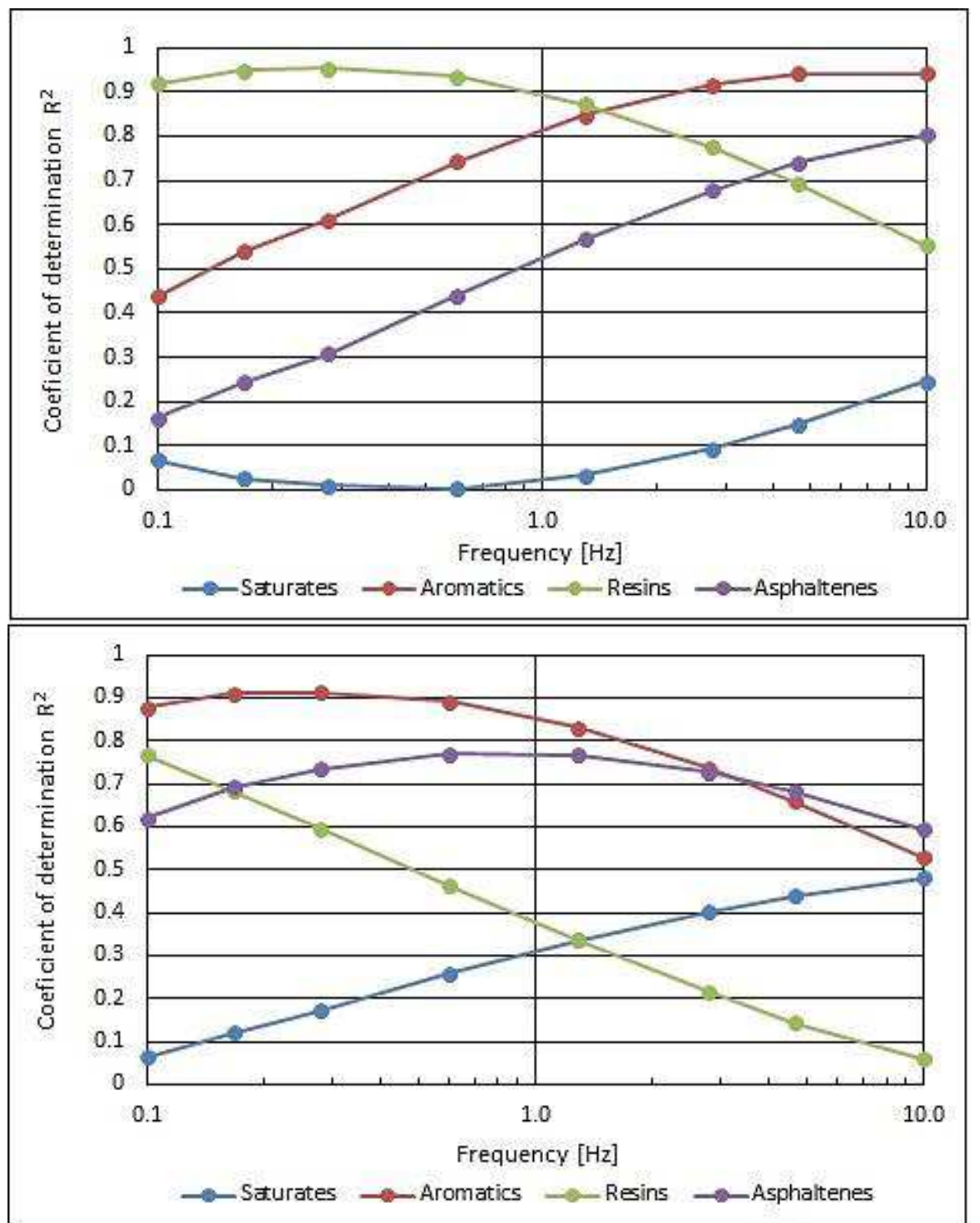

Fig. 7: Coefficient of determination for the elastic (left) and plastic (right) part of the shear complex modulus (temperature $80^{\circ} \mathrm{C}$ ).

The graphical presentation of the coefficients of determination derived for the plastic part of the shear complex modulus also proves the effect of the frequency. The stable trend can be observed for saturates and resins. The $R^{2}$ values for saturates are increasing with frequency. However, the highest $R^{2}$ value is not sufficiently high to suppose the effect of this compound on the value of the shear modulus. The $R^{2}$ values for the resins decrease with frequency. The significant values $(0.8-0.7)$ can be observed at the very low frequencies (less than $0.15 \mathrm{~Hz}$ ). The $R^{2}$ values at the higher frequencies indicate the marginal effect of this compound on the plastic part of the shear complex modulus. The trend for the aromatics and asphaltenes is the same. The raising of the $R^{2}$ values from the frequency of $0.1 \mathrm{~Hz}$, then the decrease when the frequency is above $0.3 \mathrm{~Hz}$ (aromatics) or $0.6 \mathrm{~Hz}$ (asphaltenes). 
Both compounds can be assessed as affecting the numeric value of the plastic part of the shear complex modulus up to the frequency of $3 \mathrm{~Hz}$.

\section{Conclusions}

The investigation was focused on the relationship between the chemical (group) composition of the bitumen and its shear complex modulus. Two paving grade bitumens and two polymer (SBS) modified bitumens were tested. The SARA and elementary analysis proved the small differences among the bitumens. Nevertheless, the DSR test performed at the various frequencies and temperatures demonstrated the variation in the shear complex modulus and its elastic and plastic part.

The effect of the chemical composition of the bitumen on its rheological properties was investigated using the regression analysis. In the first stage, the coefficient of determination was determined for the frequency of $1.29 \mathrm{~Hz}$ and all test temperatures.

The significant effect on the elastic part of the complex modulus was determined only at the high temperatures $\left(60\right.$ and $\left.80^{\circ} \mathrm{C}\right)$. The aromatics, resins and asphaltenes were identified as the influencing compounds. The important effect was also noted for the resins at the temperatures of 5 and $15{ }^{\circ} \mathrm{C}$. It was also concluded that the effect of the saturates on the elastic part of the shear complex modulus is marginal.

The effect of the aromatics and asphaltenes on the plastic part of the shear complex modulus was identified only at the temperature of $80{ }^{\circ} \mathrm{C}$. The effect of these two compounds at other temperatures seems to be unimportant. The significant effect of the resins was stated for the temperatures of $15{ }^{\circ} \mathrm{C}$ and $5{ }^{\circ} \mathrm{C}$. Their effect at other temperatures can be supposed as marginal. The negligible effect of the saturates on the plastic part of the shear complex modulus was deducted.

The regression analysis of the chemical composition of the bitumen and the parts of the shear complex modulus at the temperature of $80{ }^{\circ} \mathrm{C}$ proved that the frequency of the DSR test can be a factor affecting the level of the relationship between the group composition of the bitumen and its rheological properties. It was concluded, for the elastic part of the complex modulus, that the aromatics and asphaltenes are important for the frequencies above $0.6 \mathrm{~Hz}$ and $3 \mathrm{~Hz}$ respectively. The effect of the resins is important in the frequencies below $3 \mathrm{~Hz}$.

The effect of the frequency was also identified for the plastic part of the shear complex modulus. The effect of the saturates increases with frequency. However, the content of the saturates does not relate to the values of the plastic part of the shear modulus. The significant effect of the resins was observed at the very low frequencies (less than $0.15 \mathrm{~Hz}$ ). At the higher frequencies, the resins have a marginal effect on the plastic part of the shear complex modulus. The aromatics and asphaltenes were assessed as the compounds affecting the numeric value of the plastic part of the shear complex modulus up to the frequency of $3 \mathrm{~Hz}$.

\section{Acknowledgement}

This work was supported by the Slovak Research and Development Agency under the contract No. SK-CN-2017-0037 and the Ministry of Science and Technology of China under the contract No. 2018.8-7.

\section{References}

[1] ADORJÁNYI, K. - FÜLEKI, P.: Investigation of coherence between empirical and rheological properties of bitumens with dynamic shear rheometer tests. $5^{\text {th }}$ Eurasphalt \&Eurobitume Congress, 2012, paper No. A5EE-439.

[2] LIU, G. et al.: Evaluating the rheological properties of PMB containing RA binders from surfacelayer asphalt mixtures to be recycled. Construction and Building Materials, Vol. 49, 2013, pp. 8 14, ISSN 0950-0618.

[3] LIU, G. et al.: Rheological and chemical evaluation on the ageing properties of SBS polymermodified bitumen: From the laboratory to the field. Construction and Building Materials, Vol. 51, 2014, pp. 244-248, ISSN 0950-0618.

[4] COUFALÍK, P.: Rheological properties of bituminous binders (in Czech). Dissertation thesis. VUT Brno, 2017. 
[5] DAŠEK, O. et al.: Usage of advanced functions of Dynamic Shear Rheometer for the selection of a suitable binder for asphalt mixtures. Asphalt Pavements - Proceedings of the International Conference on Asphalt Pavements, ISAP 2014. 1. Raleigh, USA: CRC Press/Balkema, Taylor \& Francis Group, 2014. pp. 995-1004, ISBN 978-1-138-02693-3.

[6] MERINO-GARCIA, D. et al.: Petrophase 2009 panel discussion on standardization of petroleum fractions. Energy Fuels, Vol. 24 (4), 2010, pp. 2175 - 2177.

[7] LESUEUR, D.: The colloidal structure of bitumen: consequences on the rheology and on the mechanisms of bitumen modification. Adv Colloid Interface Sci, Vol. 145 (1-2), 2009, pp. 42 - 82.

[8] KESHMIRIZADEH. E.: Determination of Saturates, Aromatics, Resins and Asphaltenes (SARA) Fractions in Iran Crude oil Sample with Chromatography Methods: Study of the Geochemical Parameters. Journal of Applied Chemical Research, Vol. 7 (4), 2013, pp. 15-24.

[9] HUNTER, R. N. - SELF, A. - READ, J.: The Shell Bitumen Handbook. Thomas Telford Publishing London, 2015.

[10] NEUMANN, H. J.: Bitumen und seine Anwendung. Expert Verlag Grafenau, 1981.

[11] HOFKO, B. et al.: Impact of maltene and asphaltene fraction on mechanical behaviour and microstructure of bitumen. Mater Struct., Vol. 49, 2015, pp. 1 - 13, 10.1617/s11527-015-0541-6.

[12] WEIGEL, S. - STEPHAN, D.: Bitumen as required - the dream of a designed binder. $6^{\text {th }}$ Eurasphalt \& Eurobitume Congress, 2016. (DOI): dx.doi.org/10.14311/EE.2016.405.

[13] HERMADI, M. et al.: The Effect of Saturates on Rheological and Aging Characteristics of Bitumen. World Academy of Science, Engineering and Technology, Vol. 6, 2012.

[14] RADENBERG, M. - GEHRKE, M. - NYTUS, N.: Einfluss der chemischen, rheologischen und physikalischen Grundeigenschaften von Straßenbaubitumen auf das Adhäsionsverhalten unterschiedlicher Gesteinskörnungen; AiFSchlussbericht, 2014.

[15] EUROPEAN STANDARD EN1426:1999. Methods of tests for petroleum and its products. Bitumen and bituminous binders. Determination of needle penetration.

[16] EUROPEAN STANDARD EN1427:1999. Bitumen and bituminous binders. Determination of the softening point. Ring and Ball method.

[17] EUROPEAN STANDARD EN 14770:2012. Bitumen and bituminous binders. Determination of complex shear modulus and phase angle. Dynamic Shear Rheometer (DSR). 